\title{
Real-Time Implementation of Solar Inverter with Novel MPPT Control Algorithm for Residential Applications
}

\author{
Ayaz Ahmad ${ }^{1}$, Rajaji Loganathan ${ }^{2}$ \\ ${ }^{1}$ Singhania University, Pacheri Bari, India \\ ${ }^{2}$ P.B. College of Engineering, Chennai, India \\ Email: rajaji.loganathan@yahoo.com
}

Received June 8, 2013; revised July 8, 2013; accepted July 15, 2013

Copyright (C) 2013 Ayaz Ahmad, Rajaji Loganathan. This is an open access article distributed under the Creative Commons Attribution License, which permits unrestricted use, distribution, and reproduction in any medium, provided the original work is properly cited.

\begin{abstract}
Solar energy is a fast growing energy resource among the renewable energy resources in the market and potential for solar power is huge to contribute towards the power demand almost in all the countries. To capture the maximum power from the sun light in order to generate maximum power from the inverter, control system must be an equally efficient with the well designed power electronic circuits. Maximum power point tracking (MPPT) control system in general is taking care of extraction of maximum power from the sun light whereas current controller is mainly designed to optimize the inverter power to feed to power grid. In this paper, a novel MPPT algorithm using neuro fuzzy system is presented to ensure the maximum MPPT efficiency in order to ensure the maximum power across the inverter terminals. Simulation and experimental results for residential solar system with power electronic converters and analysis have been presented in this paper in order to prove the proposed algorithm.
\end{abstract}

Keywords: PV Cells; Solar Inverter; MPPT Control; DCDC Converter and Current Controller

\section{Introduction}

Solar energy is the fastest growing renewable energy market which will meet the energy demand across the globe. Photovoltaic (PV) panels are feeding the power either to battery or to the power grid through the power converters and they are termed as off-grid solar converters and on-grid solar converters respectively. In off grid solar system, PV panel output power is converted into DC power by means of boost converter and stored in a battery. For low power applications, off grid solar energy system is very much used. A grid-connected PV system is made up of an array of panels mounted on rack-type and these panels are connected in series or parallel to achieve optimal voltage and current, and feed into an inverter transforming direct current into alternating current at a phase and at the same voltage as the grid. Operating voltage of an array of panels is varied based on the rating of inverter and the maximum value of this voltage even up to $700 \mathrm{~V}$. Figure 1 shows the block diagram of solar inverter system which comprises of array of solar panels, DCDC converter (DCDC power conversion), DCAC converter (DCAC power conversion) and both are coupled with the help DC link capacitor. This solar inverter system is connected to Power utility system known as "Power Grid". The solar inverter is equipped with a maximum power point tracking (MPPT) system that constantly adjusts the entry voltage to the characteristics of the PV modules, which vary according to temperature and solar radiation. MPPT system is normally available in DCDC converter and based on the power point tracking DCDC converter will deliver the DC power to DCAC converter for the AC power conversion. DC link voltage between DCDC and DCAC converter is maintained within the specified value by control systems [1].

In general, DCDC converter converts the photovoltaic power (DC) to controllable DC power and DCAC converter converts controlled DC power into controlled AC power which will be transferred to power grid. This research work designs and develops novel control strategies for better MPPT tracking at any kind of sun light fluctuations and also for optimum current control in DCAC converter in order to achieve lower harmonics level when inverter gets connected to power grid. Unlike wind energy system, solar energy system does not need any mechanical or thermal interlink and produces electrical power from sun light. Photovoltaic (PV) cells are interconnected together and formed as solar panel which 


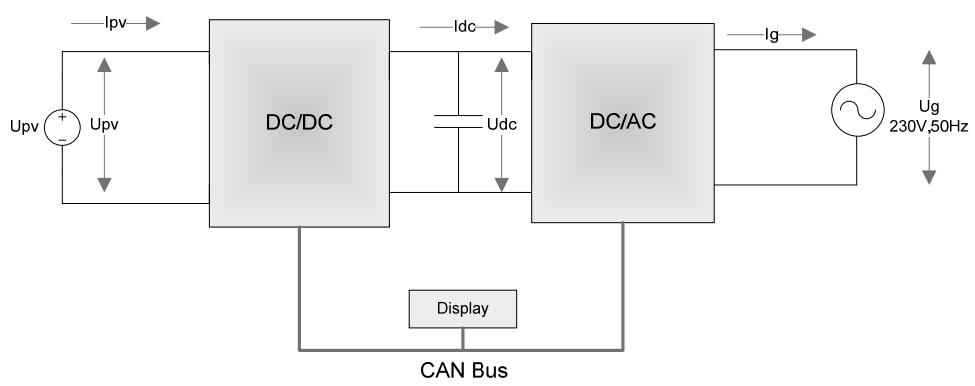

Figure 1. System Overview.

captures sun light directly and DC voltage is produced based on the number of cells connected. Normally, each $\mathrm{PV}$ cell produces $0.3 \mathrm{~V}$ to $0.6 \mathrm{~V}$ DC voltage from the captured sun light [2]. To get the maximum DC voltage of $400 \mathrm{~V}$, minimum $667 \mathrm{PV}$ cells are required to capture the sunlight. Although, PV panels are capable of generating the required amount of DC voltage, DC voltage output from the PV cells is also depending on the solar irradiation. To capture the maximum voltage from the available irradiation level, an efficient maximum power point tracking algorithm should be deployed so that it will track the irradiation level periodically. Figure 2 shows the Voltage (Upv) - Power (Ppv) characteristics of a typical PV Panel.

\section{MPPT Control Algorithms}

With reference to different types of MPPT control algorithms, Perturb and Observe (P \& O) algorithm, constant voltage $(\mathrm{CV})$ algorithm and Incremental Conductance (INC) algorithms are commonly used algorithms in MPPT control systems [3-6]. Generally, MPPT controller gives the reference voltage from the inputs of PV voltage, PV current and the DC link voltage as shown in Figure 3. Adaptive MPPT approach has also been presented by many authors [7-11] which is more suitable to non-linear irradiation conditions. INC algorithm is also used by many researchers and presented in $[12,13]$. One of the artificial intelligence techniques such as Fuzzy control is proposed in [14] and in this reference author has implemented the proposed methodology using field programmable gate array (FPGA). Based on the understanding from the previous work and current scenario, it is well understood that efficient and dynamic MPPT control is very much required to get the maximum output across the input terminals. In this paper hence author proposed novel MPPT approach using adaptive neuro fuzzy approach to get the optimized reference voltage from the MPPT controller.

\section{Adaptive Neuro Fuzzy MPPT Algorithm}

Hybrid learning control algorithm in adaptive neuro

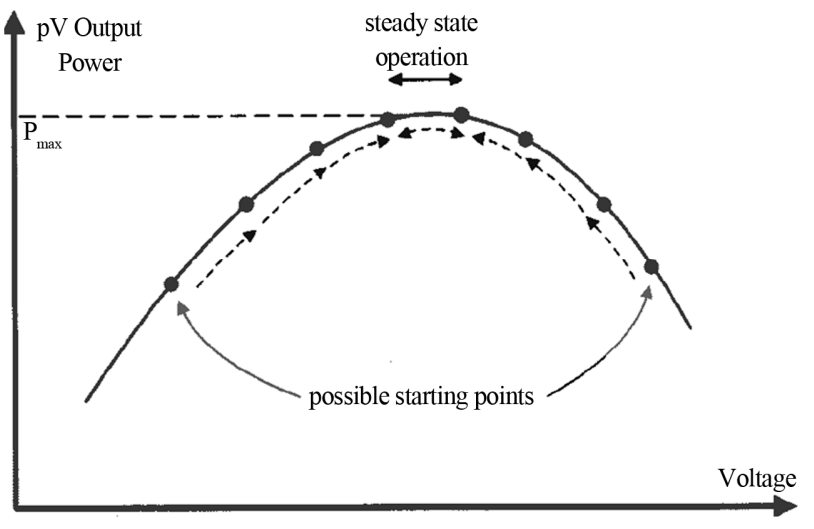

Figure 2. P-V characteristics of a PV module.

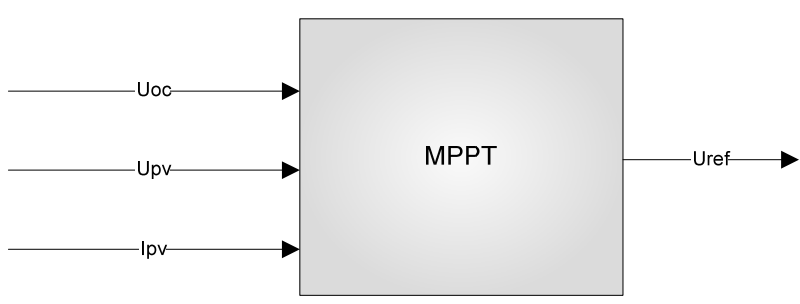

Figure 3. Input/Output Block for MPPT subsystem in DC/DC module.

fuzzy system is used to identify the membership functions parameters of single output. Figure 4 shows the block diagram of the PV model with MPPT algorithm. The control block takes input from the PV panel and computes the duty cycle for the $\mathrm{DC} / \mathrm{DC}$ converter. Inside the control block, MPPT block computes the reference voltage and proportional controller computes the duty cycle of PWM based on the Panel Voltage (Upv) and reference voltage calculated from MPPT block. Neuro fuzzy technique is incorporated in MPPT block which gives the optimized reference voltage to proportional controller. Figure 5 shows the simulink model of proposed controller with three inputs and single output. Combination of least squares and back propagation descent methods are used to train the membership function parameters [15]. 

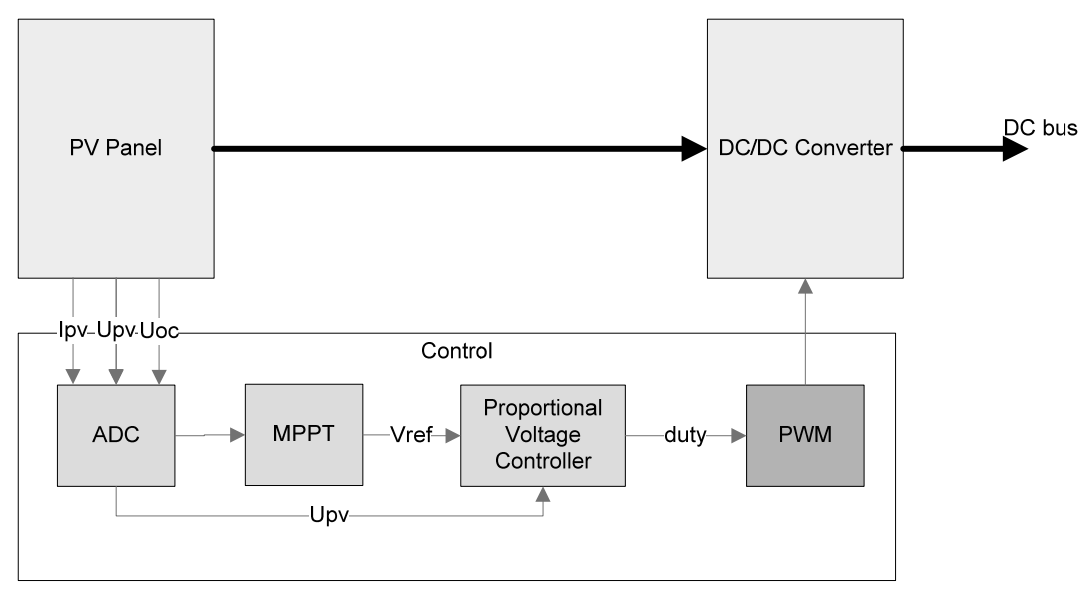

Figure 4. Block diagram of MPPT implementation.

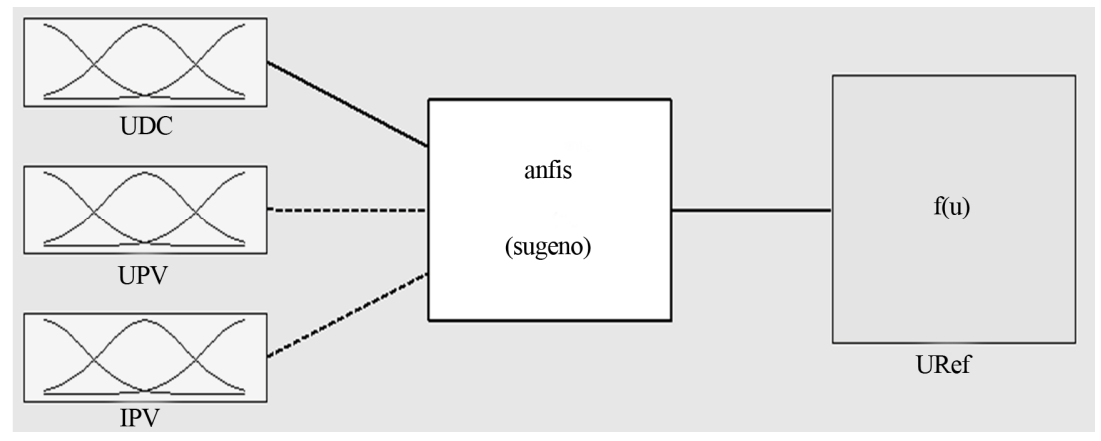

Figure 5. ANFIS based MPPT controller.

\section{Simulation Procedure, Results and Discussions}

IGBT (Insulated Gate Bipolar Transistor) based PV inverter is considered for Simulation of proposed control algorithm. In this inverter, 3 nos. of DCDC converters which are connected in parallel and single DCAC module rated $6 \mathrm{~kW}$ are considered for the simulation. Simulation model of complete system is shown in Figure 6. The intensity of the sunlight $\left(\mathrm{W} / \mathrm{m}^{2}\right)$ is given as input in the form of Square wave or Sine wave to the PV Module. PV Module is duplicated with Ipv $=0$, to measure the open circuit voltage of the PV module for the given light intensity. The Output of the PV module is connected to the $\mathrm{DC} / \mathrm{DC}$ converter. The reference voltage of DC link is also given as input to the DC/DC Converter. The voltage and Current from PV Module are sampled and given as input to the MPPT block and voltage of PV module is given to the Proportional controller. The MPPT block calculates the $\mathrm{U}_{\text {ref }}$ and it is fed to Voltage controller. The proportional voltage controller block calculates the duty cycle for PWM signal based on the PV Panel voltage and Uref. The inputs to the MPPT system in the simulation model are PV Panel Voltage (Ppv), Panel Current (Ipv) and Open Circuit Voltage of the PV Panel (Uoc).

Tracking Error and Efficiency are calculated based on the Equations (1) and (2).

$$
\begin{gathered}
\text { Tracking Efficiency }(\%)=\frac{\text { Ppv }}{\text { Pmpp }} \times 100 \\
\text { Tracking Error }(\%)=\frac{\text { Pmpp-Ppv }}{\text { Pmpp }} \times 100
\end{gathered}
$$

The Matlab function block implements the combined two method hybrid algorithm for MPP Tracking. The output of the MATLAB function would be the voltage at which MPP occurs (Vmpp), which is given as reference to the proportional voltage controller. For DCDC converter circuit, an average model of DCDC converter is taken for simulation. The irradiance of $500 \mathrm{~W} / \mathrm{m}^{2}$ was considered for static condition and variation of $300 \mathrm{~W} / \mathrm{m}^{2}$ is considered over $500 \mathrm{~W} / \mathrm{m}^{2}$. In Figure 7, Square wave of $0.5 \mathrm{~Hz}$ varying between $500 \mathrm{~W} / \mathrm{m}^{2}$ and $800 \mathrm{~W} / \mathrm{m}^{2}$ irradiation is shown. It is assumed that intensity is varying between $500 \mathrm{~W} / \mathrm{m}^{2}$ and $800 \mathrm{~W} / \mathrm{m}^{2}$ every second. Though this case is practically not possible as huge variation of intensity in shorter duration, it has been considered for measuring the effectiveness of MPPT algorithm to track the actual Maximum Power Points in the worst case scenario. In Figure 8, Power was dropped to $250 \mathrm{~W}$ during transient state and attained the steady state value of 700 W with 1 second. Though there exists a fluctuation in 


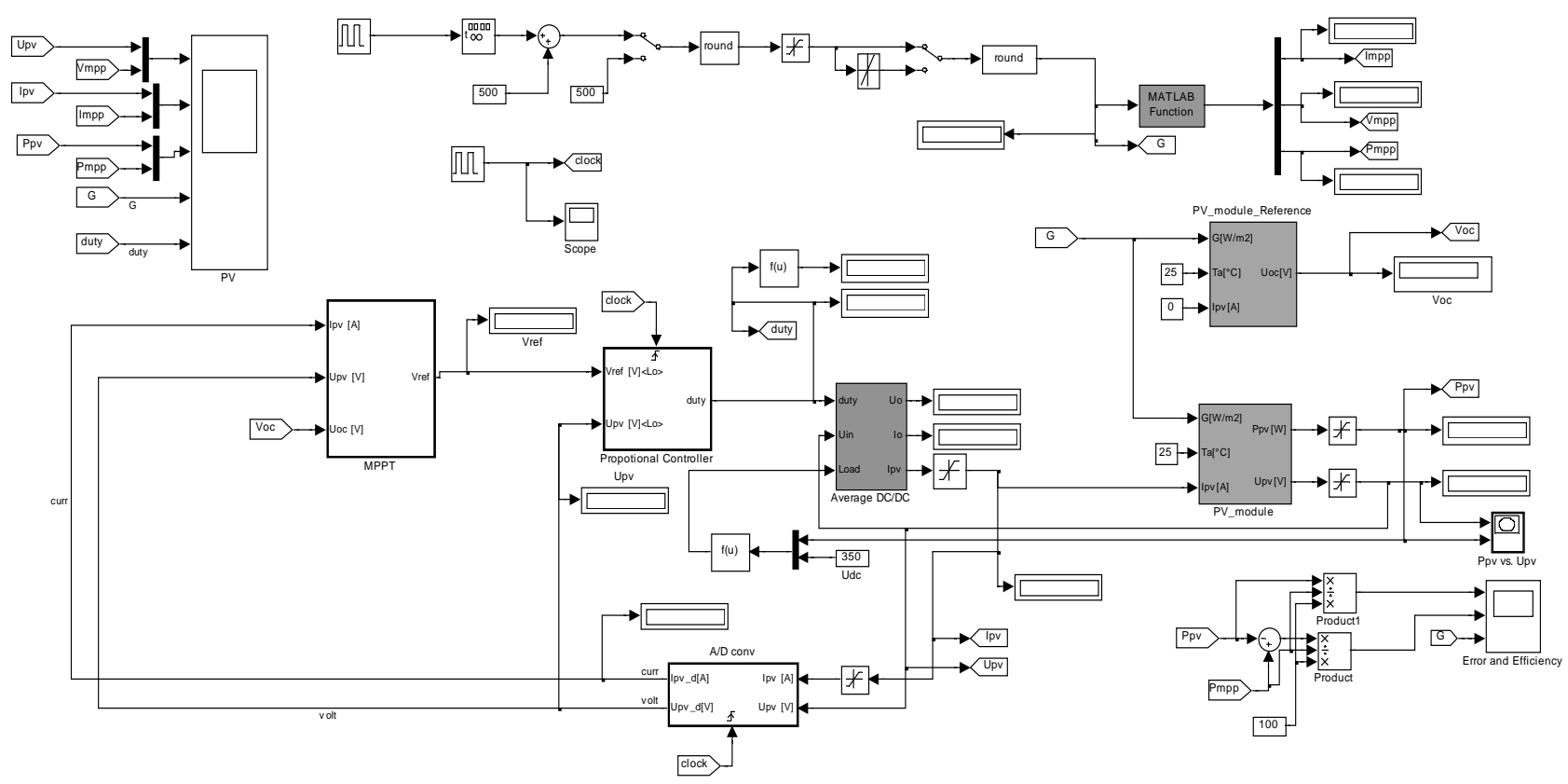

Figure 6. Simulink Model of PV panel, MPPT and DC/DC Converter.

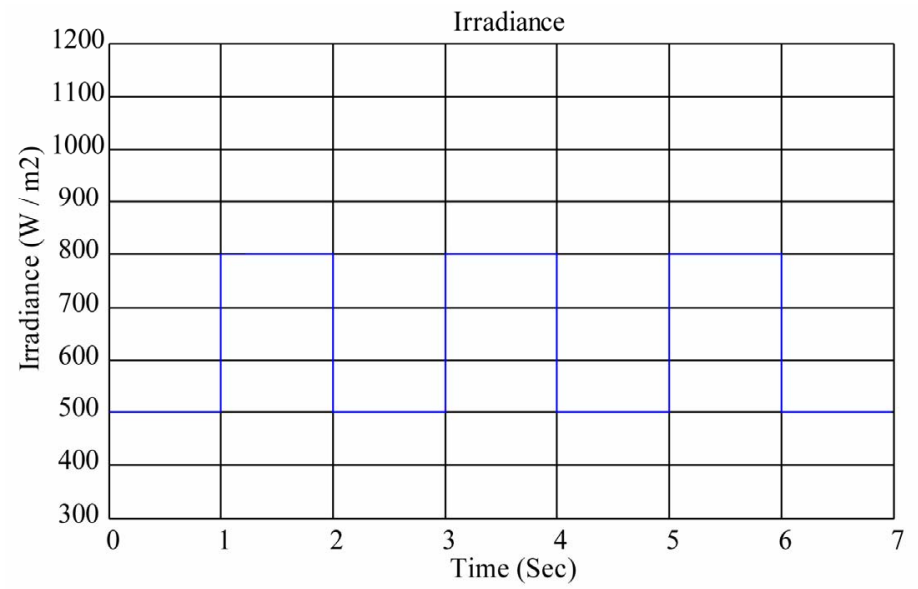

Figure 7. Solar Light Intensity with varying irradiance.

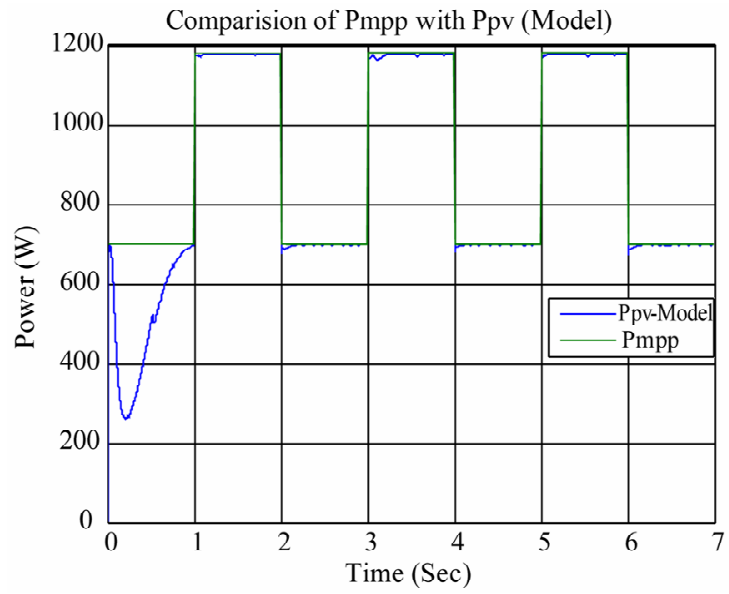

Figure 8. Comparison of actual PV Power (Ppv) and Calculated Maximum power (Pmpp). 
voltage and current, the amount of power delivered remains constant and it close or almost same as the calculated maximum power. But during the transition state the amount of produced power was less than the maximum power. Hence efficiency will be less during the transition state whenever the sunlight intensity changes. Figures 9 and $\mathbf{1 0}$ show percentage of Error and Efficiency obtained from the model under dynamic conditions. It has been observed that the efficiency was dropped to the $37 \%$ during the start up and settled around $99.9 \%$ after the transition time of 1 second. Similarly the error in the calculated set point and actual PV power reached maximum of $63 \%$ and settled with in 1 second. During the steady state condition the error was found to be less than $1 \%$. However during in sunlight intensity, efficiency was dropped to $97 \%$ and Error was increased to $3 \%$. It's very clearly observed that the frequent change in Set point will affect the inverter efficiency. Figure 11 shows the comparison of maximum power tracked and operating power at the $50 \%$ of maximum irradiance level. Figure 12 shows the comparison of voltage at maximum power tracked and the operating voltage at the $50 \%$ of maximum irradiance level. Figure 13 shows the comparison of Maximum Power tracked and operating power at the $100 \%$ of maximum irradiance level. Figure 14 shows the comparison of voltage at maximum power tracked and the operating voltage at the $100 \%$ of maximum irradiance level.

\section{Experimental Implementation, Results and Discussion}

Specification of solar inverter considered for the simulation has also been considered to design the experimental system. Figure 15 shows the experimental circuit of DCDC converter which has the H-bridge with MOSFETs. Solar inverter hardware consists of MOSFET based

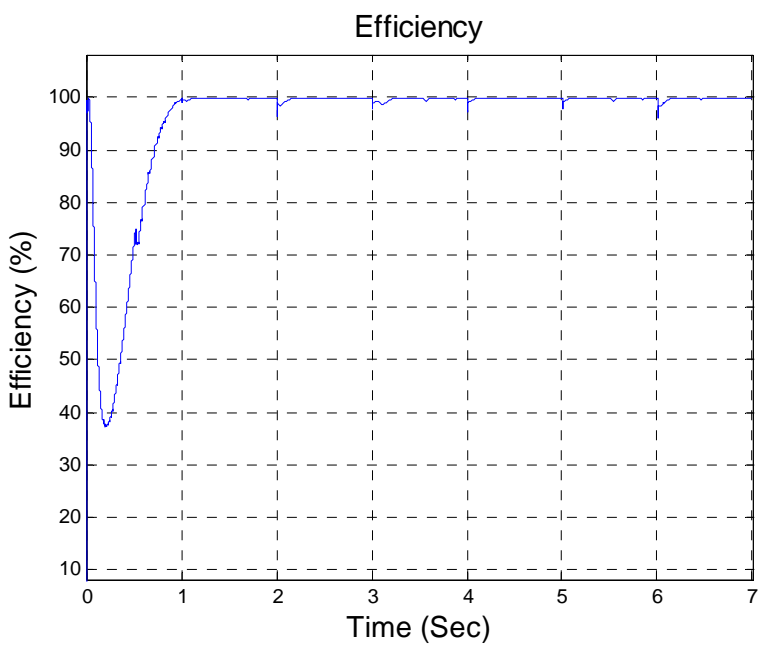

Figure 9. Efficiency under dynamic condition.

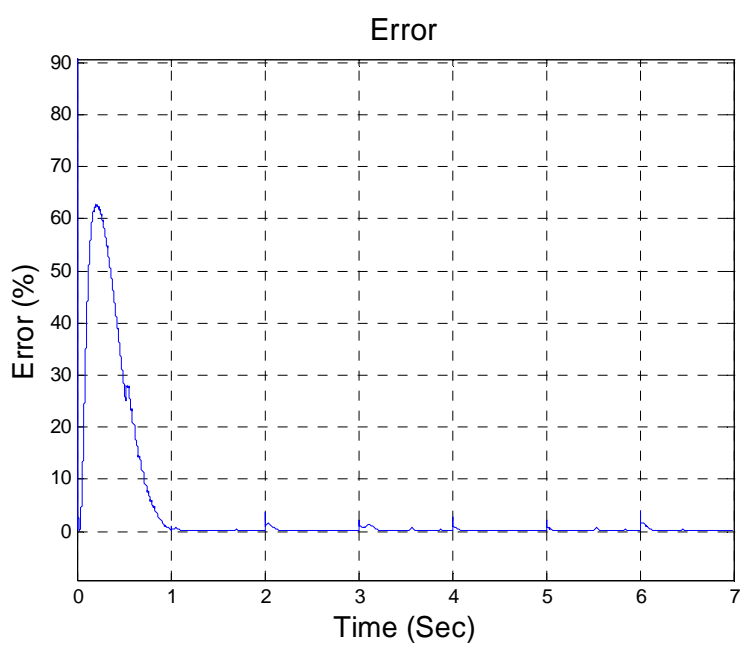

Figure 10. Error under dynamic condition.

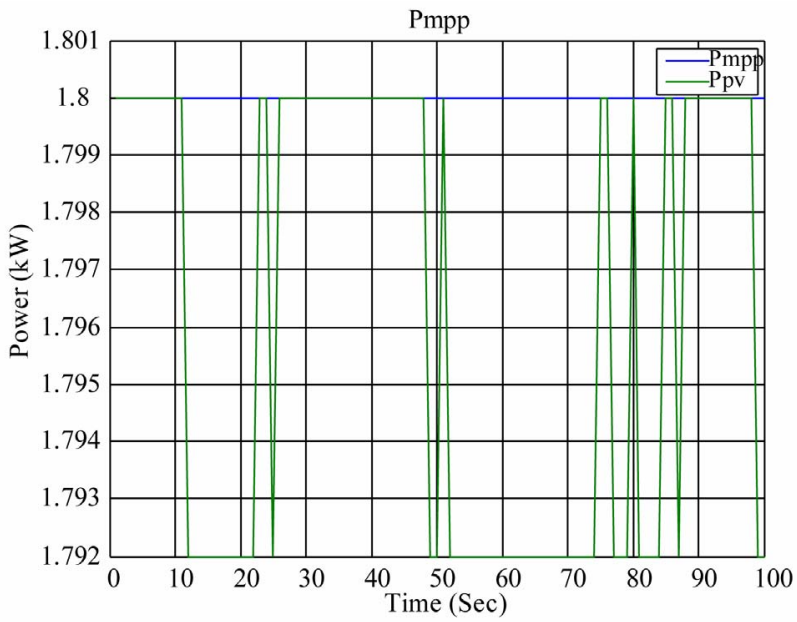

Figure 11. Comparison of MPP Power and Operating Power at $50 \%$ of irradiance.

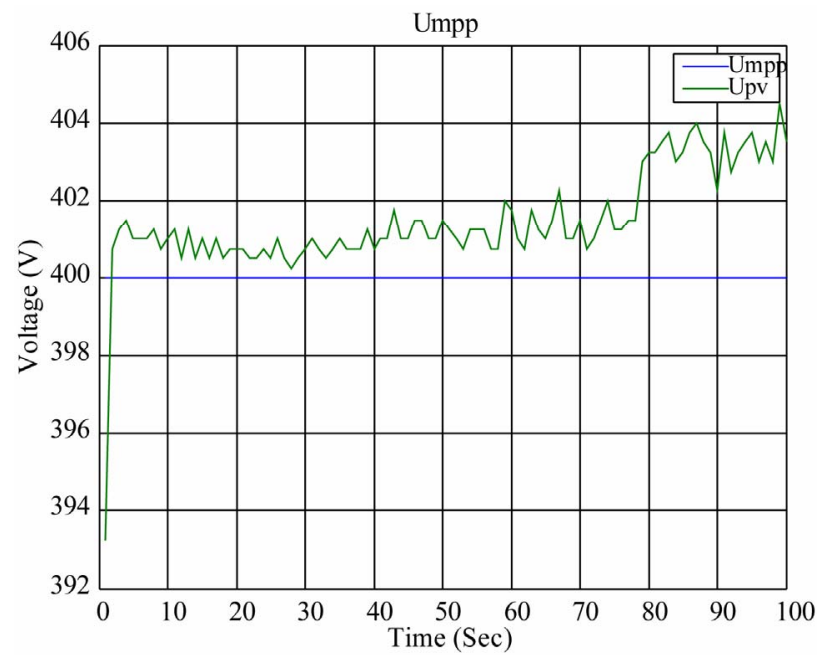

Figure 12. Comparision of MPP Voltage and Operating Voltage at $50 \%$ of irradiance. 


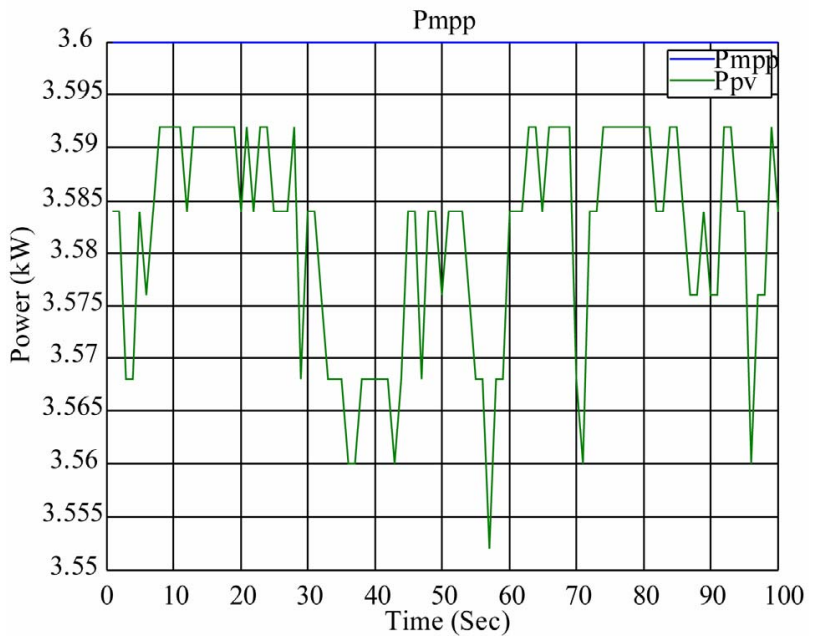

Figure 13. Comparision of MPP Power (Pmpp) and Operating Power (Ppv) at $100 \%$ of irradiance.

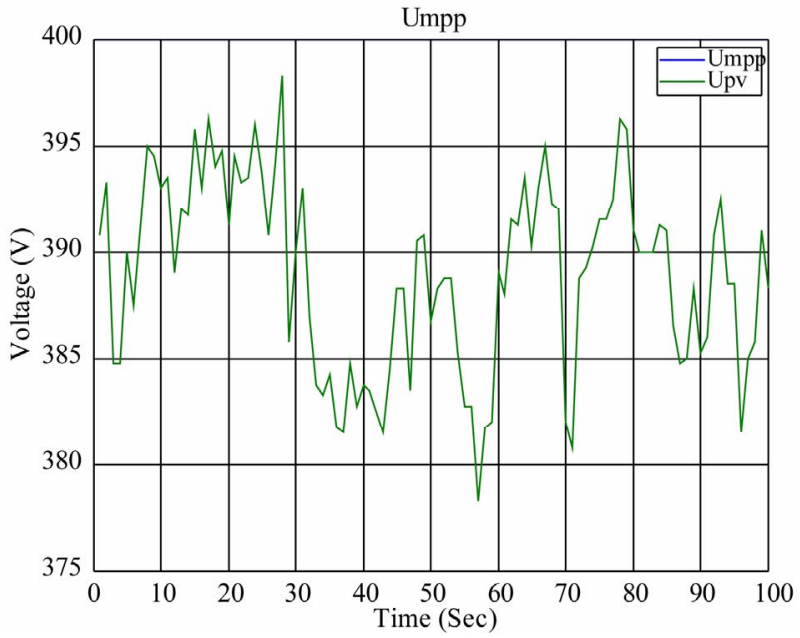

Figure 14. Comparision of MPP Voltage (Umpp) and Operating Voltage (Upv) at $\mathbf{1 0 0 \%}$ of irradiance.

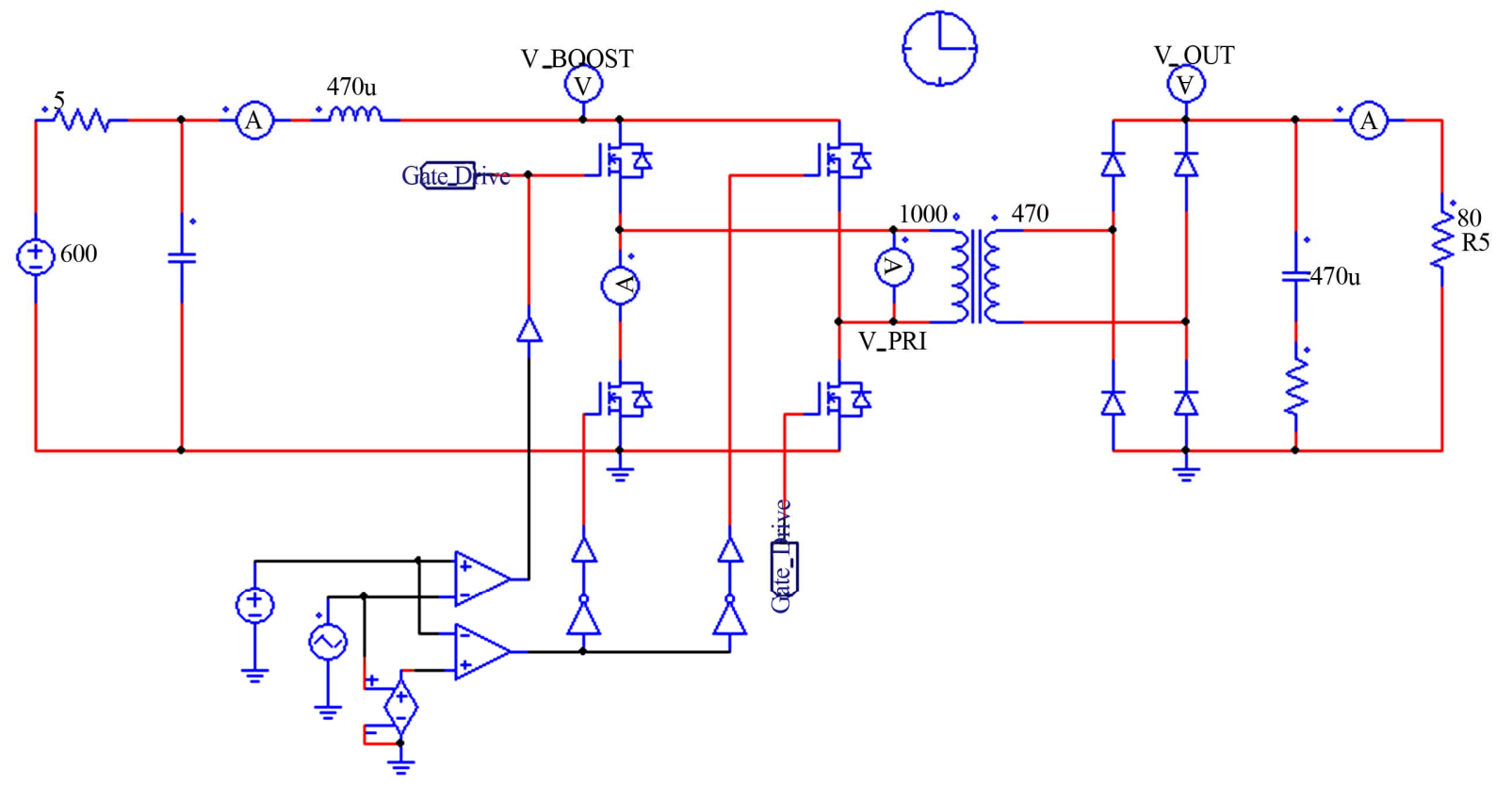

Figure 15. Experimental layout of DCDC converter.

DCDC converter, DC link capacitor, IGBT based DCAC inverter and LCL filter. This power electronic circuit combination is integrated and input to DCDC converter is captured from the PV cell and output of inverter is connected to the power grid. Major part of experimental set up consists of DCDC board, DC Link capacitor, DCAC board and LCL filter. $6 \mathrm{~kW}$ DCDC board consists of three $2 \mathrm{~kW}$ DCDC boards connected in parallel in order to optimize the operation of the board. Based on the power availability at the solar panel, no. of boards in DCDC board would be selected and maximum power captured from DCDC board could be $6 \mathrm{~kW}$. PV voltage range is varied from $180 \mathrm{~V}$ to $400 \mathrm{~V}$ and DCDC con- verter is boosting the voltage whenever it is required and this voltage is appeared across the DC link capacitor as DC link voltage. DCDC converter acts as boost converter which operates at $90 \mathrm{KHz}$ and the full bridge operates at $45 \mathrm{KHz}$. In the DC converter, the input Photovoltaic (PV) voltage is fed to H-bridge power module with a front end filter and boost section. The input voltage is boosted with the boost inductor. The Power module consists of an $\mathrm{H}$ bridge MOSFET, a current sense resistor and diode bridge rectifier. In the first cycle initially all the MOSFETs in the H-bridge are switched on to charge the boost Inductor and the voltage is boosted. In the off time, diagonal MOSFETs will be switched off and the voltage is 
seen across the transformer. Similarly in the next cycle, after the boost inductor is charged, other diagonal MOSFETs will be switched off. The output of power module is isolated using Transformer and fed to the inverter section. Transformer has a turn ratio of 0.75 . The controller contains advanced peripherals like high precision PWM outputs and ADCs for implementing control loops. The ADC measures variables, such as the PV output voltage and current, and then adjusts the DC/DC or DC/AC converter by changing the PWM duty cycle.
C2000 is used to read the ADC and adjust the PWM within a single clock cycle so that real time control is achieved. Figure 16 shows the output voltage waveforms of DCDC converter circuit and for convenience, captured experimental data has been considered and various output waveforms drawn.

Booster voltage, voltage at transformer primary and voltage at transformer secondary are shown in Figure 16. Figure 17 shows the PV and IV curves captured from the photovoltaic simulator for the given irradiance level
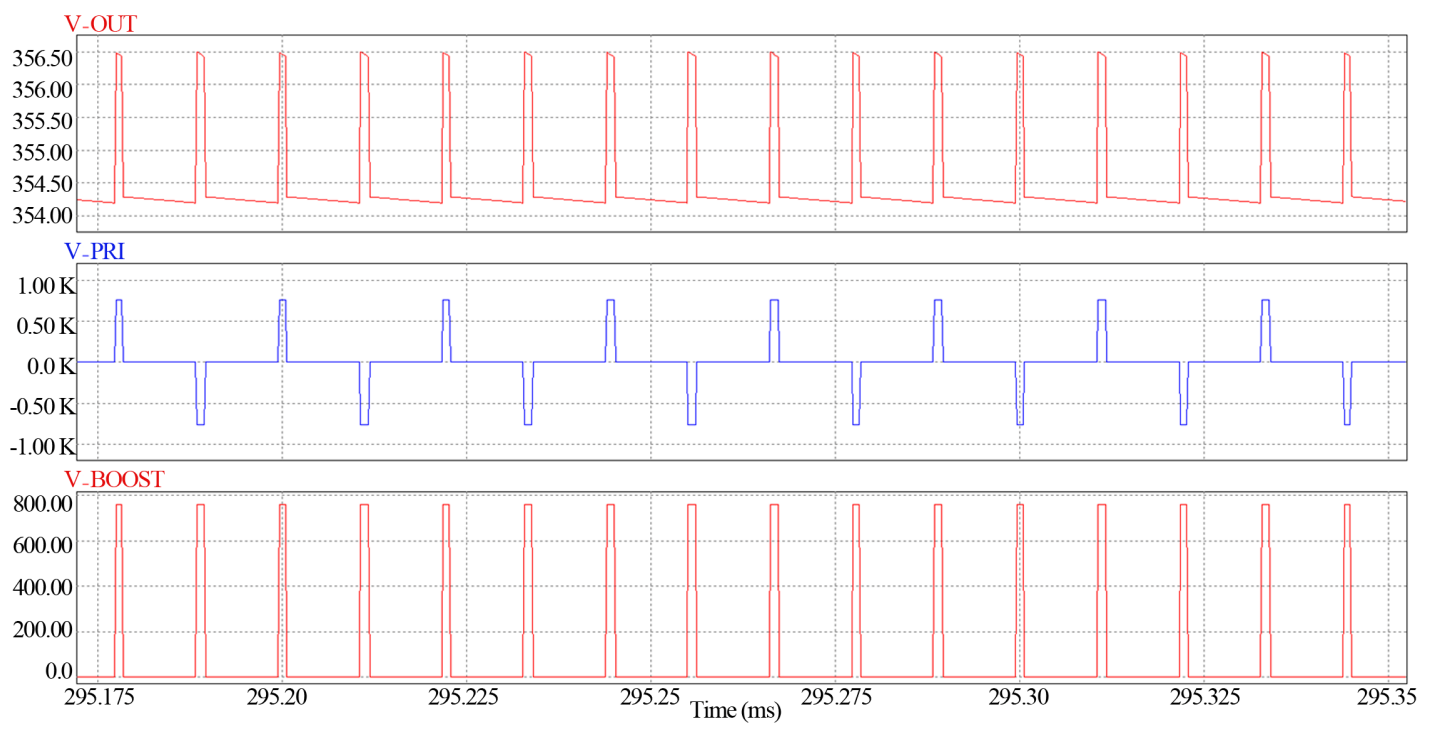

Figure 16. Experimental DCDC converter voltage waveforms.

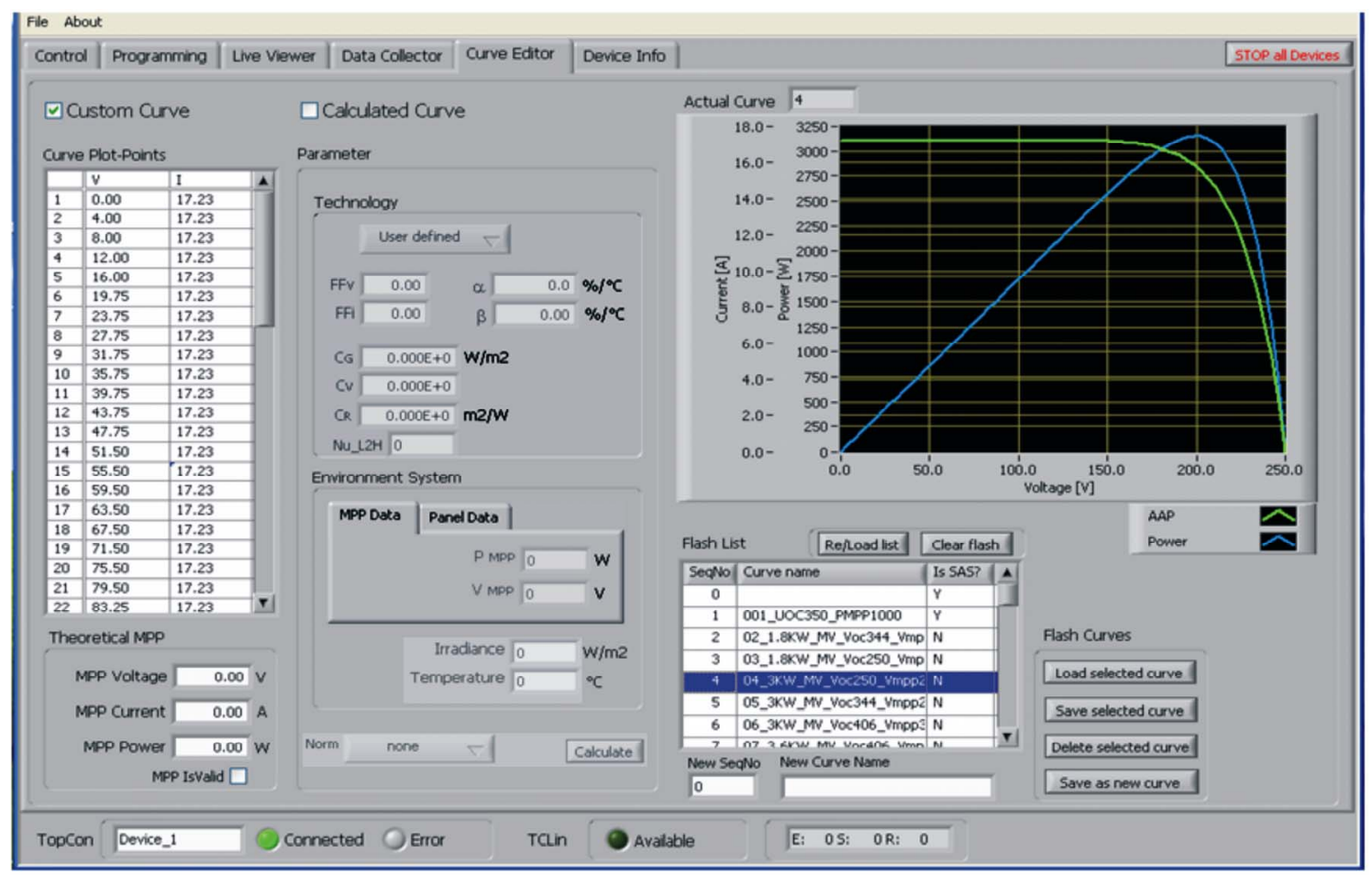

Figure 17. PV Simulator output. 
of $500 \mathrm{~W} / \mathrm{m}^{2}$. Figure 18 shows the voltage and current output at the PV inverter. From this figure, it is clearly understood that current is lagging voltage at $0.8 \mathrm{PF}$ and this lagging power is fed to power grid.

Table 1 shows the duty cycle ranges for various input and output voltage levels and based on this duty cycle values, DCDC converter output voltage values will be delivered from the given input voltage. Table 2 shows the MPP tracking efficiency without changing irradiance value at different power levels. Values are given in Table 2 shows the capability of proposed MPPT algorithm.

\section{Conclusion}

An efficient Maximum power point tracking control algorithm using adaptive neuro fuzzy technique is presented in this paper. For the proposed control algorithm, $6 \mathrm{~kW}$ rated single phase inverter is considered for modeling and simulation in Matlab/Simulink environment. Dynamic variation of irradiation level is considered as input and tracking efficiency is computed. Based on the simulation and experimental results, it is clearly observed
Table 1. Duty cycle for various input and output voltage ranges

\begin{tabular}{|c|c|c|c|c|c|c|c|}
\hline & \multicolumn{7}{|c|}{ Input Voltage } \\
\hline \multirow{12}{*}{ 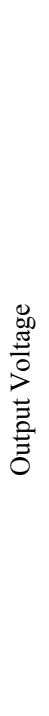 } & D & 250 & 290 & 330 & 370 & 410 & 450 \\
\hline & 350 & 0.46 & 0.38 & 0.29 & 0.21 & 0.12 & 0.04 \\
\hline & 355 & 0.47 & 0.39 & 0.30 & 0.22 & 0.13 & 0.05 \\
\hline & 360 & 0.48 & 0.40 & 0.31 & 0.23 & 0.15 & 0.06 \\
\hline & 365 & 0.49 & 0.40 & 0.32 & 0.24 & 0.16 & 0.08 \\
\hline & 370 & 0.49 & 0.41 & 0.33 & 0.25 & 0.17 & 0.09 \\
\hline & 375 & 0.50 & 0.42 & 0.34 & 0.26 & 0.18 & 0.10 \\
\hline & 380 & 0.51 & 0.43 & 0.35 & 0.27 & 0.19 & 0.11 \\
\hline & 385 & 0.51 & 0.44 & 0.36 & 0.28 & 0.20 & 0.12 \\
\hline & 390 & 0.52 & 0.44 & 0.37 & 0.29 & 0.21 & 0.13 \\
\hline & 395 & 0.53 & 0.45 & 0.37 & 0.30 & 0.22 & 0.15 \\
\hline & 400 & 0.53 & 0.46 & 0.38 & 0.31 & 0.23 & 0.16 \\
\hline
\end{tabular}

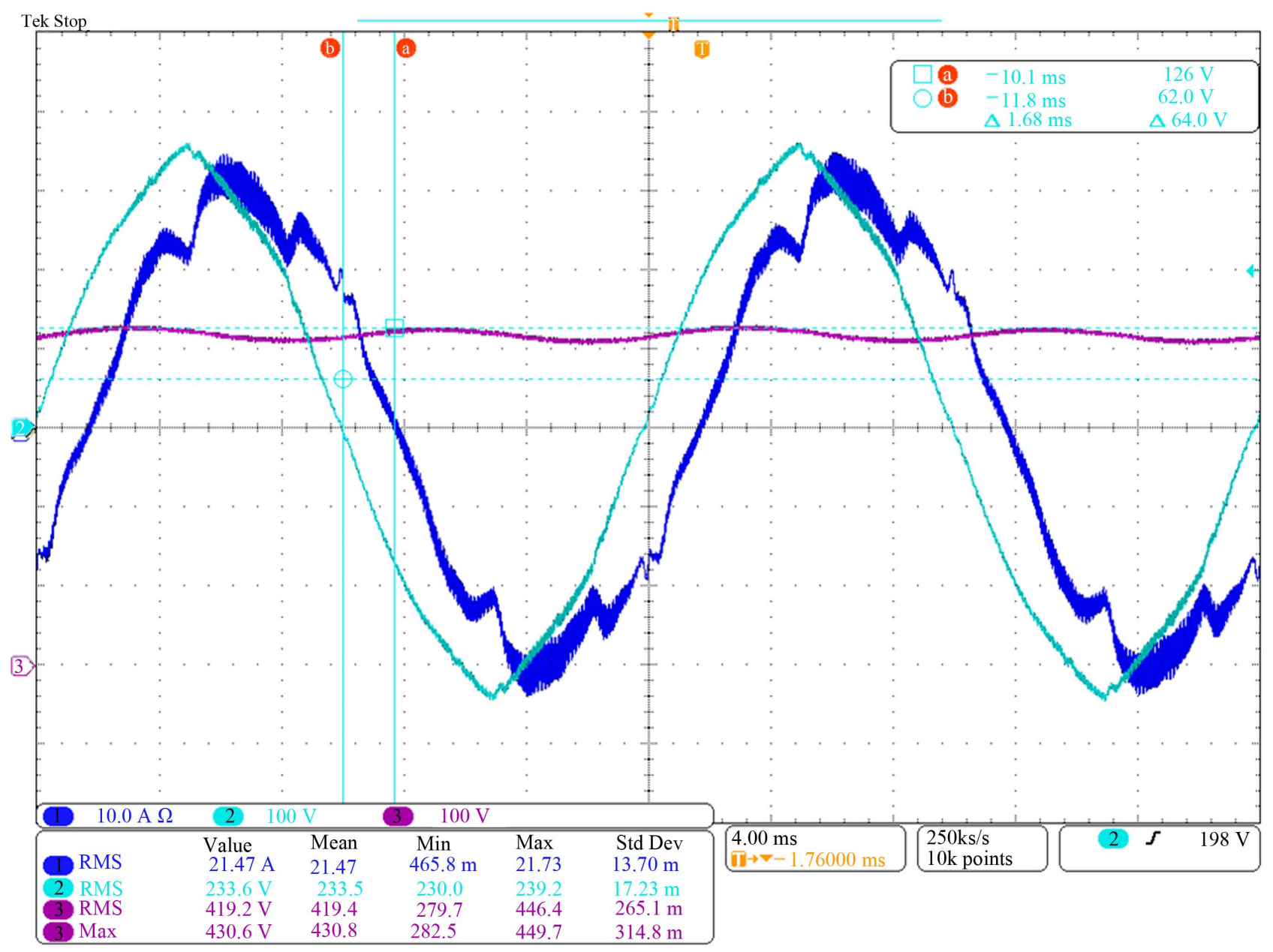

Figure 18. Voltage and current waveforms of DCAC inverter circuit. 
Table 2. MPP Tracking Efficiency without change in Irradiance@ different Power Levels.

\begin{tabular}{ccc}
\hline S. No & \% of Power & Efficiency (\%) \\
\hline 1 & 5 & 100 \\
2 & 10 & 99.58 \\
3 & 20 & 99.72 \\
4 & 25 & 99.32 \\
5 & 30 & 99.75 \\
6 & 50 & 99.75 \\
7 & 75 & 99.21 \\
8 & 100 & 99.43 \\
\hline
\end{tabular}

that proposed control technique would be the best one to capture the maximum power across the input terminals since the tracking efficiency is achieved as $99.9 \%$.

\section{REFERENCES}

[1] H. Patel and V. Agarwal, "MPPT Scheme for a PV-Fed Single-Phase Single-Stage Grid-Connected Inverter Operating in CCM With Only One Current Sensor," IEEE Transactions on Energy Conversion, Vol. 24, No. 1, 2009, pp. 256-263. doi:10.1109/TEC.2008.2005282

[2] G. Escobar, et al., "PV Current Sensorless MPPT for a Single-Phase PV Inverter," IECON 2011-The 37th Annual Conference on IEEE Industrial Electronics Society, Melbourne, 7-10 November 2011, pp. 3906-3911.

[3] N. Kasa, T. Iida and L. Chen, "Fly Back Inverter Controlled by Sensorless Current MPPT for Photovoltaic Power System," IEEE Transactions on Industrial Electronics, Vol. 52, No. 4, 2005, pp. 1145-1152. doi:10.1109/TIE.2005.851602

[4] O. Lopez-Lapena, Penella, M.T. and M. Gasulla, "A New MPPT Method for Low-Power Solar Energy Harvesting," IEEE Transactions on Industrial Electronics, Vol. 57, No. 9, 2010, pp. 3129-3138. doi:10.1109/TIE.2009.2037653

[5] R. Leyva, C. Alonso, I. Queinnec, A. Cid-Pastor, D. Lagrange and L. Martinez-Salamero, "MPPT of Photovoltaic Systems Using Extremum-Seeking Control," IEEE Transactions on Aerospace and Electronic Systems, Vol. 42 , No. 1, 2006, pp. 249-258.
doi:10.1109/TAES.2006.1603420

[6] N. Mutoh, M. Ohno and T. A. Inoue, "Method for MPPT Control While Searching for Parameters Corresponding to Weather Conditions for PV Generation Systems," IEEE Transactions on Industrial Electronics, Vol. 53, No. 4, 2006, pp. 1055-1065. doi:10.1109/TIE.2006.878328

[7] N. Fermia, D. Granozio, G. Petrone and M. Vitelli, "Predictive \& Adaptive MPPT Perturb and Observe Method," IEEE Transactions on Aerospace and Electronic Systems, Vol. 43, No. 3, 2007, pp. 934-950. doi:10.1109/TAES.2007.4383584

[8] N. Femia, G. Petrone, G. Spagnuolo and M. Vitelli, “A Technique for Improving P\&O MPPT Performances of Double-Stage Grid-Connected Photovoltaic Systems," IEEE Transactions on Industrial Electronics, Vol. 56, No. 11, 2009, pp. 4473-4482. doi:10.1109/TIE.2009.2029589

[9] A. K. Abdelsalam, A. M. Massoud, S. Ahmed, P. N. Enjeti, "High-Performance Adaptive Perturb and Observe MPPT Technique for Photovoltaic-Based Microgrids," IEEE Transactions on Power Electronics, Vol. 26, No. 4, 2011, pp. 1010-1021. doi:10.1109/TPEL.2011.2106221

[10] D. Sera, R. Teodorescu and J. Hantschel, "Optimized Maximum Power Point Tracker for Fast-Changing Environmental Conditions," IEEE Transactions on Industrial Electronics, Vol. 55, No. 7, 2008, pp. 2629-2637. doi:10.1109/TIE.2008.924036

[11] G. Carannante, C. Fraddanno, M. Pagano and L. Piegari, "Experimental Performance of MPPT Algorithm for Photovoltaic Sources Subject to Inhomogeneous Isolation," IEEE Transactions on Industrial Electronics, Vol. 56, No. 11, 2009, pp. 4374-4380. doi:10.1109/TIE.2009.2019570

[12] Q. Mei, M. W. Shan, L. Y. Liu and J. M. Guerrero, “A Novel Improved Variable Step-Size Incremental-Resistance MPPT Method for PV Systems," IEEE Transactions on Industrial Electronics, Vol. 58, No. 6, 2011, pp. 2427-2434. doi:10.1109/TIE.2010.2064275

[13] F. R. Liu, S. X. Duan, F. Liu, B. Y. Liu and Y. Kang, "A Variable Step Size INC MPPT Method for PV Systems," IEEE Transactions on Industrial Electronics, Vol. 55, No. 7, 2008, pp. 2622-2628. doi:10.1109/TIE.2008.920550

[14] Z. Cheng, H. Z. Yang and Y. Sun, "FPGA-Based PV Systems Fuzzy MPPT Control Algorithm," 2010 Seventh International Conference on Fuzzy Systems and Knowledge Discovery (FSKD), Vol. 3, Yantai, 10-12 August 2010, pp. 1244-1248. doi:10.1109/FSKD.2010.5569127

[15] Matlab/Simulink-Tool and User Guide, 201. 